\title{
Identification and characterization of recombinant inbred lines (RILs) for waterlogging tolerance in bread wheat
}

\author{
Gyanendra Singh, Pradeep Kumar, Vikas Gupta*, Bhudev Singh Tyagi, Charan Singh and \\ Gyanendra Pratap Singh \\ ICAR-Indian Institute of Wheat and Barley Research, Karnal - 132001 (Haryana)
}

\section{Article history}

Received: 14 Jul., 2020

Revised: 15 Sep., 2020

Accepted: 3 Dec., 2020

\section{Citation}

Singh G, P Kumar, V Gupta, BS Tyagi, C Singh and GP Singh 2020. Identification and characterization of recombinant inbred lines (RILs) for waterlogging tolerance in bread wheat. Journal of Cereal Research 12(3): 229-238. http://doi.org/ $10.25174 / 2582-2675 / 2020 / 102300$

*Corresponding author

Email: vikas.gupta@icar.gov.in

\begin{abstract}
Waterlogging is an abiotic stress that affects wheat yields throughout the world. Inbuilt tolerance towards it will be an effective and economical approach. The aim of the present study was to identify the promising genotypes from recombinant inbred line (RILs) populations based on specific traits contributing to waterlogging tolerance for sustaining wheat yields. 340 RILs were developed by crossing BH 1146 , source known for waterlogging tolerance and a high yielding widely adapted variety DBW16 following a single seed descent (SSD) method upto 7 generations of recombination cycles. The experiment was conducted using an augmented block design under normal and waterlogging conditions. The waterlogging condition was created at four important growth stages viz., seedling, tillering, reproductive and grain-filling stage by stagnating water for one week in the waterlogged experiment. The traits viz., plant height, tillers number per meter, spike weight, 1000-grain weight, biological yield and harvest index exhibited a significant and positive correlation with grain yield under waterlogging, indicating that these traits contributed significantly towards grain yield under waterlogging condition. Twelve lines (SSD-06, SSD -15, SSD-17, SSD-24, SSD-28, SSD-94, SSD-99, SSD-130, SSD-134, SSD-245, SSD-253, and SSD-264) were selected based on the high mean and least reduction percent for grain yield, biological yield, and 1000-grain weight. Similarly, 05 lines (SSD-27, SSD-30, SSD80 , SSD-130, and SSD-303) identified to be promising for grain yield, biological yield, and tillers per meter over the superior check. The selected RILs could be used as donors in the hybridization programme for enhancing tolerance in wheat cultivars under waterlogging stressed environments.
\end{abstract}

Keywords: Bread wheat, grain yield, recombinant inbred lines, traits association, waterlogging tolerance.

\section{Introduction}

Waterlogging is an important abiotic stress affecting wheat yields throughout the world, especially irrigated and high rainfall and low lying areas/environments.

Waterlogging tolerance is known as the ability of a genotype(s) to maintain high growth rates, accumulation of high biomass and higher grain yield under waterlogging conditions (Setter and Waters, 2003). The adverse effects of waterlogging may be reduced by the cultivation of tolerant wheat cultivars in waterlogged areas.

Waterlogging affects wheat yields in areas receiving heavy rainfall and poorly drained soil (Zhang et al., 2015).

The soil waterlogging stress condition affects about 10 percent of land area at the global level; however, 25 percent area comes under alone in wheat in the world 
(Powell et al., 2012). In India, waterlogging and salinity affect 5.6 million hectare area (Gupta, 2002).Under the waterlogging condition, grain yield was reduced by about 50 percent (Singh et al., 2019) in bread wheat. Including grain yield, some researchers reported adverse effects of waterlogging on spike density (Ali et al., 2012); root biomass (Araki et al., 2012); plant height, tillers number per meter, grain number per spike and 1000-grain weight (Singh et al., 2018a). The wheat crop is very sensitive to waterlogging particularly during the seedling, flowering, and grain filling periods. There are various stresses namely, limitations to gas exchange, mineral nutrient deficiencies, and microelement toxicities which affects the plants under waterlogged condition (Setter and Waters, 2003; Setter et al., 2009). However, the response of wheat plant under waterlogging was shown by restricted root growth, reduced dry matter accumulation, prematurely senescing leaves, wilting, producing sterile florets, reducing tillering, and lowering of kernel weight which caused reduction in grain yield under waterlogged conditions (Jiang et al., 2008; Zhang et al., 2006). In the early growth stage of wheat, the maintenance of high biomass under waterlogging condition is an important agronomic character (Parelle $e t$ al., 2010). The duration, intensityand developmental stage at which waterlogging treatment is applied to determine the reduction percentage in grain yield (Arguello et al., 2016; Dickin and Wright, 2008). High yielding genotypes provides a potential opportunity for increasing grain yields in target environments, but excellent genetic material for future crop improvement can be achieved from both high yielding and waterlogging tolerant genotypes, i.e. genotypes with the highest grain yield in waterlogged relative to drained/normal conditions (Singh et al., 2018b). However, the development of tolerant wheat cultivars to waterlogging is an effective and economical approach to improve grain yield under waterlogging conditions. A successful and effective selection will depend upon the presence of genetic variability in breeding materials and association among various component traits and grain yield. The traits associations study is useful to breeders in selecting the genotypes possessing groups of desired traits (Singh et al., 2014). However, breeders need relatively a simple method for selecting the lines/ cultivars which exhibited waterlogging tolerance. Keeping in view the changing climatic era and the large area under waterlogging stress at the global level, the present study was taken up for sustaining the wheat productivity level through genotype developmentand also to identify the traits that contribute significantly to yield under targeted waterlogging stress environments.

\section{Materials and methods}

\subsection{Experimental Site}

The experiment for the present study was conducted from November to mid-April under two contrast environments (normal as well as waterlogging conditions) during the year 2016-17 at ICAR-Indian Institute of Wheat and Barley Research (IIWBR), Karnal, Haryana, India.

\subsection{Experimental materials and design}

The materials used in this experiment comprising 340 recombinant inbred lines (RILs) and 05 checks (DBW 16, BH 1146, HD 2967, HD 2009 and Kharchia 65), where DBW 16 and HD 2967 are high yielding varieties under timely sown irrigated conditions, while BH 1146 and Kharchia 65 are also released varieties and also identified to be waterlogging tolerant. The materials were planted in augmented block design in a given environment (Federer, 1956). In an augmented block design, the seeds of the tested lines were planted only with one replication for each environment, while each check used, were planted with five replications for local error control (Stringer and Cullis, 2002). In this study, each line (tested lines and checks) was planted in a one-row plot of $2.0 \mathrm{~m}$ length with aspacing of $23 \mathrm{~cm}$ between rows and $10 \mathrm{~cm}$ between plants within a row. The field of the experiment was divided into five equal blocks and each block consisted of 68 tested RILs and five checks. The same set of checks was planted in each block with test lines. All the recommended agronomic practices were followed to raise good crop stand under normal and waterlogging conditions except waterlogging treatment.

\subsection{Creation of waterlogging condition}

To create a waterlogged condition, the stagnation of water was allowed for one week at four different growth stages of the crop viz., at seedling stage (21 days after sowing), at tillering stage (40 days after sowing), at the reproductive stage (60 days after sowing) and at grain-filling stage (75 days after sowing) as waterlogging conditions reported(Singh et al., 2018a) in wheat.

\subsection{Recording the observations}

The observations were recorded on nine yield component 
Table 1. Analysis of variance of bread wheat RILs population for yield components under normal and waterlogging conditions

\begin{tabular}{|c|c|c|c|c|c|c|c|c|c|c|c|}
\hline \multirow[t]{2}{*}{ Source } & \multirow[t]{2}{*}{ D F } & \multicolumn{10}{|c|}{ Mean square } \\
\hline & & Conditions & $\begin{array}{l}\text { Days to } \\
\text { heading }\end{array}$ & $\begin{array}{l}\text { Days to } \\
\text { maturity }\end{array}$ & $\begin{array}{l}\text { Plant } \\
\text { height }\end{array}$ & $\begin{array}{l}\text { Tillers } \\
\text { per meter }\end{array}$ & $\begin{array}{l}\text { Spike } \\
\text { weight }\end{array}$ & $\begin{array}{l}1000- \\
\text { grain } \\
\text { weight }\end{array}$ & $\begin{array}{l}\text { Biological } \\
\text { yield }\end{array}$ & $\begin{array}{l}\text { Harvest } \\
\text { index }\end{array}$ & $\begin{array}{l}\text { Grain } \\
\text { yield }\end{array}$ \\
\hline \multirow[t]{2}{*}{ Lines } & \multirow[t]{2}{*}{344} & Normal & $17.01^{* *}$ & $17.95^{* *}$ & $162.15^{* *}$ & $309.79^{* *}$ & $8.09^{* *}$ & $0.24^{* *}$ & $2166.16^{* *}$ & $32.25^{* *}$ & $439.93^{* *}$ \\
\hline & & Waterlogging & $31.06^{* *}$ & $26.49^{* *}$ & $152.66^{* *}$ & $418.97^{* *}$ & $8.78^{* *}$ & $0.23^{* *}$ & $2293.42^{* *}$ & $52.45^{* *}$ & $370.73^{* *}$ \\
\hline \multirow[t]{2}{*}{ Blocks } & \multirow[t]{2}{*}{4} & Normal & 0.06 & 1.56 & 9.27 & 8.26 & 1.05 & 0.04 & 216.50 & 3.50 & 16.50 \\
\hline & & Waterlogging & 1.20 & 0.50 & 8.79 & 10.84 & 0.68 & 0.01 & 194.00 & 6.63 & 6.14 \\
\hline \multirow[t]{2}{*}{ Error } & \multirow[t]{2}{*}{16} & Normal & 0.93 & 0.94 & 6.40 & 13.98 & 0.76 & 0.03 & 79.62 & 6.41 & 30.87 \\
\hline & & Waterlogging & 0.85 & 1.47 & 4.25 & 14.06 & 1.11 & 0.01 & 109.62 & 10.34 & 22.99 \\
\hline \multirow{2}{*}{$\begin{array}{l}\text { Among } \\
\text { checks }\end{array}$} & \multirow[t]{2}{*}{4} & Normal & $34.66^{* *}$ & $32.66^{* *}$ & $968.03^{* *}$ & $1128.56^{* *}$ & $25.43^{* *}$ & $0.73^{* *}$ & $2321.50^{* *}$ & $41.79^{* *}$ & $526.50^{* *}$ \\
\hline & & Waterlogging & $18.90^{* *}$ & $6.10^{*}$ & $1023.11^{* *}$ & $1728.24^{* *}$ & $26.61^{* *}$ & $0.66^{* *}$ & $3761.50^{* *}$ & $62.18^{* *}$ & $127.74^{*}$ \\
\hline \multirow{2}{*}{$\begin{array}{l}\text { Among } \\
\text { test lines }\end{array}$} & \multirow[t]{2}{*}{339} & Normal & $16.68^{* *}$ & $17.52^{* *}$ & $152.00^{* *}$ & $274.54^{* *}$ & $7.90^{* *}$ & $0.22^{* *}$ & $2086.45^{\text {** }}$ & $31.42^{* *}$ & $404.91^{* *}$ \\
\hline & & Waterlogging & $31.24^{* *}$ & $26.63^{* *}$ & $142.82^{* *}$ & $370.70^{* *}$ & $8.59^{* *}$ & $0.22^{* *}$ & $2223.39^{* *}$ & $52.10^{* *}$ & $356.64^{* *}$ \\
\hline \multirow{2}{*}{$\begin{array}{l}\text { Test lines } \\
\text { vs. } \\
\text { Checks }\end{array}$} & \multirow[t]{2}{*}{1} & Normal & $59.35^{* *}$ & $106.82^{* *}$ & $377.46^{* *}$ & $8984.35^{* *}$ & $5.01^{*}$ & $2.40^{* *}$ & $28565.76^{* *}$ & $277.24^{* *}$ & $11965.72^{* *}$ \\
\hline & & Waterlogging & $17.88^{* *}$ & $60.93^{* *}$ & 6.30 & $11545.92^{* *}$ & 0.54 & $0.13^{*}$ & $20161.16^{* *}$ & $131.27^{* *}$ & $6116.94^{* *}$ \\
\hline
\end{tabular}

Indicates significance at $\mathrm{P}=0.05,{ }^{* *}$ Indicates significance at $\mathrm{P}=0.01$, Degree of Freedom (DF)

traitsviz.,days to anthesis, days to maturity, plant height $(\mathrm{cm})$, tillers number per meter, spike weight (g), 1000-grain weight $(\mathrm{g})$, biological yield per plot $(\mathrm{g})$, harvest index $(\%)$ and grain yield per plot (g) for identification and characterization of recombinant inbred lines (RIL) populationfor waterlogging tolerance in bread wheat along with checks used under both normal and waterlogging conditions.

\subsection{Statistical analysis}

The adjusted mean value of test lines was calculated as per statistical procedure (Zhang et al., 2006) for analysis of variance of augmented design using GenStat 18th Edition (VSN International Ltd, Hemel Hempstead, UK). Genetic variability and traits association among yield components and grain yield under both normal as well as waterlogging conditions were calculated with adjusted mean using statistical software STAR Version 2.0.1 (2014). The reduction percentage (RP) in grain yield and each component trait was estimated based on mathematical relationships between yield and other yield components under normal and waterlogged conditions.

Reduction percentage $(\mathrm{RP})=(\mathrm{Yp}-\mathrm{Ys}) / \mathrm{Yp} \times 100$

Where, Yp and Ys represents the mean value of the character of a particular genotype under normal and waterlogged conditions, respectively. The lower values of reduction percentage in grain yield and each component trait under waterlogged conditions represent relatively more tolerant to waterlogging conditions as compared to other genotypes. Therefore, reduction percentage in grain yield and other component traits should have negative values (low values) for the selection of superior lines under waterlogging conditions based on these mathematical relationships among grain yield and other component traits.

\section{Results and discussion}

The analysis of variance indicating the presence of significant differences $(p<0.01)$ among the tested lines, among the checks used and among tested lines vs. checks for nine yield traits studied (except plant height and spike weight among tested lines vs. checks in waterlogging condition) under both normal as well as waterlogging conditions (Table 1). The analysis of variance revealed significant variation for all the yield contributing traits studied, indicating the presence of wider genetic variability which can be used for the genetic enhancement of desired trait(s). Differential response of the tested RILs population was observed for studied yield traits under both normal and waterlogging conditions, indicating that the RILs performed differently under different conditions, and 


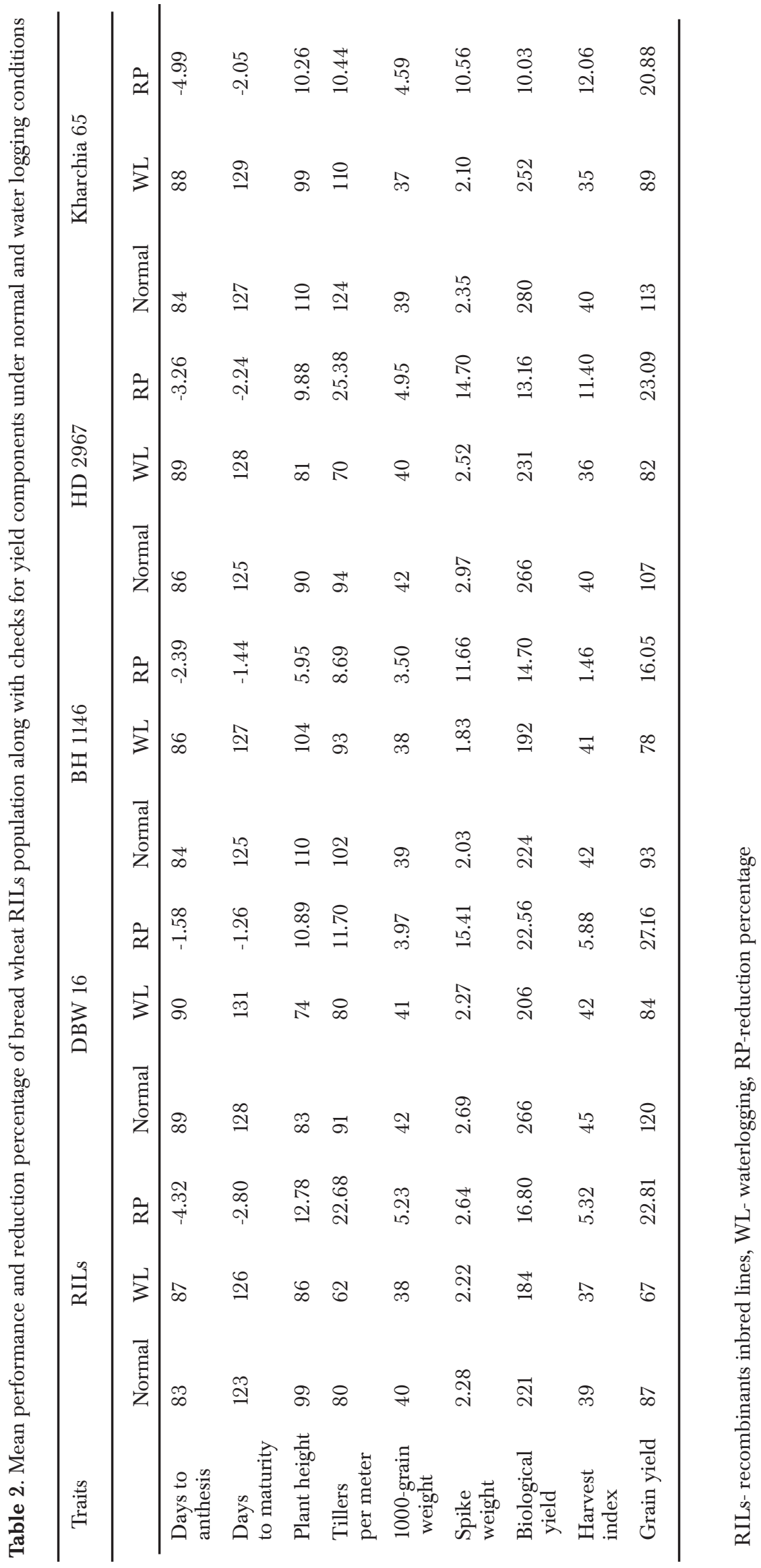


also showed the variation for waterlogging tolerance within the tested RILs population. These results were corroborated with the earlier finding (Singh et al., 2014, 2017, 2018a, 2018b), which suggested that the genetic constitution of genotypes performed differently under different conditions (normal and waterlogging) in wheat because of the different genetic constitution of each RILs.

\subsection{Genetic variability}

The performance of RILs population along with checks for yield component traits under normal and waterlogging conditions is represented. The mean for different traits is given in Table 2. All the traits showed reduced performance under waterlogged conditions as compared to the normal conditions. Some of the RILs showed superior performance under waterlogged conditions as compared to checks and are given in Table 3. The RILs SSD-C3-130, SSD-C3-94, SSD-C3-245 and SSD-C3-303 recorded lowest reduction $(<8 \%)$ in grain yield whereas the RILs SSD-C3- 130, SSD-C3-27, SSD-C3-24 recorded highest yield under waterlogged conditions among RILs and checks. There was no cross over identified with respect to the performance of RILs and checks in the waterlogged and normal conditions.

\subsection{Effect of Waterlogging on Yield Components}

The mean values for all the yield components under normal, as well as waterlogging conditions in all 344 lines including checks used in the experiment are presented in Table 2 and Fig. 2. The maximum reduction was recorded in grain yield $(22.81 \%)$ followed by tillers number per meter $(22.68 \%)$, biological yield $(16.80 \%)$, plant height (12.78\%), harvest index (5.32\%), 1000-grain weight (5.23\%) and spike weight $(2.34 \%)$ while a minimum reduction in days to anthesis $(-4.32 \%)$ and days to maturity $(-2.80 \%)$ are less sensitive traits under a waterlogging condition in SSD-RILs populations. In the present study, all the yield traits are adversely affected due to waterlogging stress conditions; but the highest reduction percentage was recorded in grain yield, biological yield, tillers number per meter, plant height, 1000-grain weight, harvest index, and spike weight. The minimum reduction percentage was recorded in two traits (days to anthesis and days to maturity). The overall performance of SSD-RILs population-based on reduction percentage in grain yield and biological yield was observed better than their one parent (DBW 16) and lower than another parent (BH 1146). Therefore, the selections based on these above traits will be useful in identifying the tolerant genotypes under waterlogging conditions.

Waterlogging stress significantly affected grain yield, biological yield, tillers per meter, plant height, and spike weight in wheat (Singh et al., 2020). In a previous study, an overall 34\% reduction in grain yield, along with a reduction in biomass, 1000-kernel weight, and kernel weight per spike in spring wheat was reported due to waterlogging (Arguello et al., 2016). However, the effect of waterlogging was found different at two different locations with the reduction in mean grain yields about 30\% at Central Soil Salinity Research Institute, Karnal location, and 75\% at Narendra Deva University of Agriculture and Technology, Faizabad location (Singh et al., 2018b). In the previous study, it is reported that grain yield and 1000-grain weight (Dickin and Wright, 2008), and spike density (Dickin et al., 2009) to be reduced by waterlogging in winter wheat. It is not necessarily that the genotypes with high yielding potential possess the tolerance genes (Zhang et al., 2017). Therefore, the RILs were selected based on high mean and less reduction in grain yield and also had higher biomass, a higher number of tillers per meter and high 1000-grain weight under waterlogging condition, which also confirmed by the earlier findings (Singh et al., 2018a) in bread wheat.

\subsection{Association studies}

Correlation coefficients were estimated among grain yield and other components traits under both normal and waterlogging conditions to observe the magnitude and direction of association among these yield components (Table 4). The significant and positive correlation was recorded for biological yield $\left(0.81^{* *} \& 0.79^{* *}\right)$, harvest index $\left(0.49^{* *} \& 0.31^{* *}\right)$, tiller number per meter $\left(0.43^{* *} \&\right.$ $\left.0.60^{* *}\right)$ and spike weight $\left(0.11^{* *} \& 0.21^{* *}\right)$ with grain yield under both normal as well as waterlogging conditions, respectively. Whereas 1000 -grain weight $\left(0.29^{* *}\right)$ and plant height $\left(0.18^{* *}\right)$ showed a significant and positive correlation with grain yield under waterlogging condition. The knowledge of association among component traits as well as with grain yield is beneficial in formulating the breeding methodology. The positive and significant correlation was recorded for tillers number per meter, spike weight, biological yield and harvest index with grain yield under both normal as well as waterlogging conditions, in addition to plant height in normal condition, while 1000 -grain weight in waterlogging condition. In the earlier study, the positive and significant association 

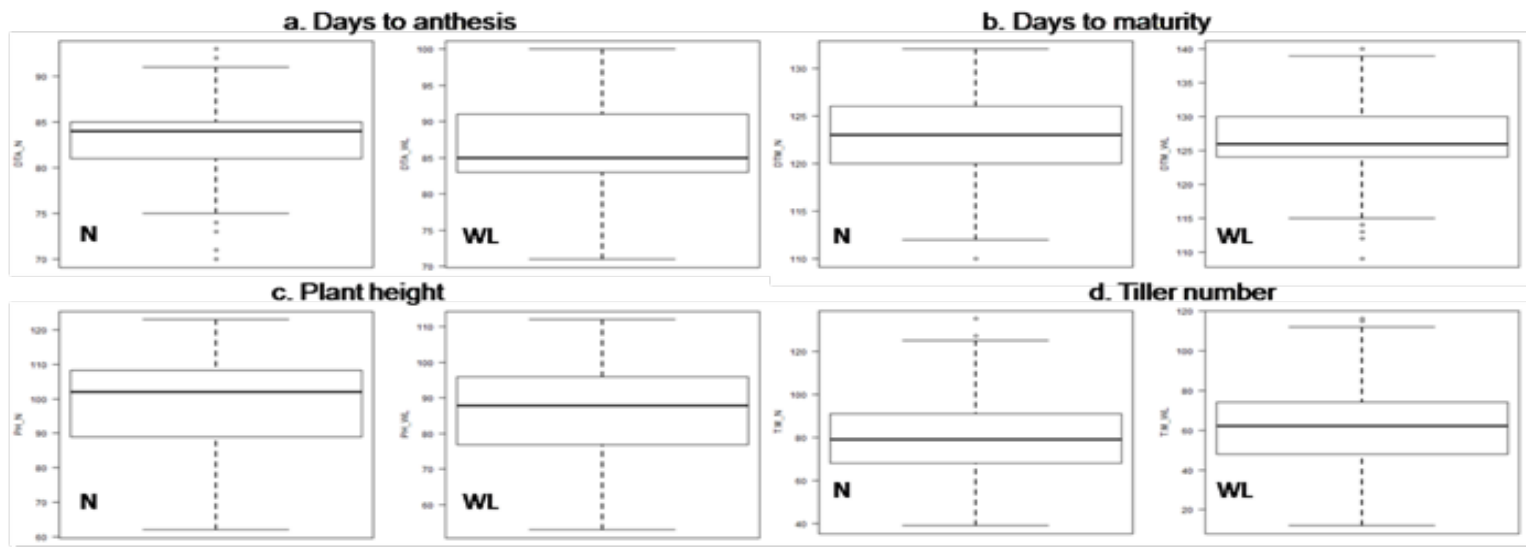

e. Thousand kemel weight
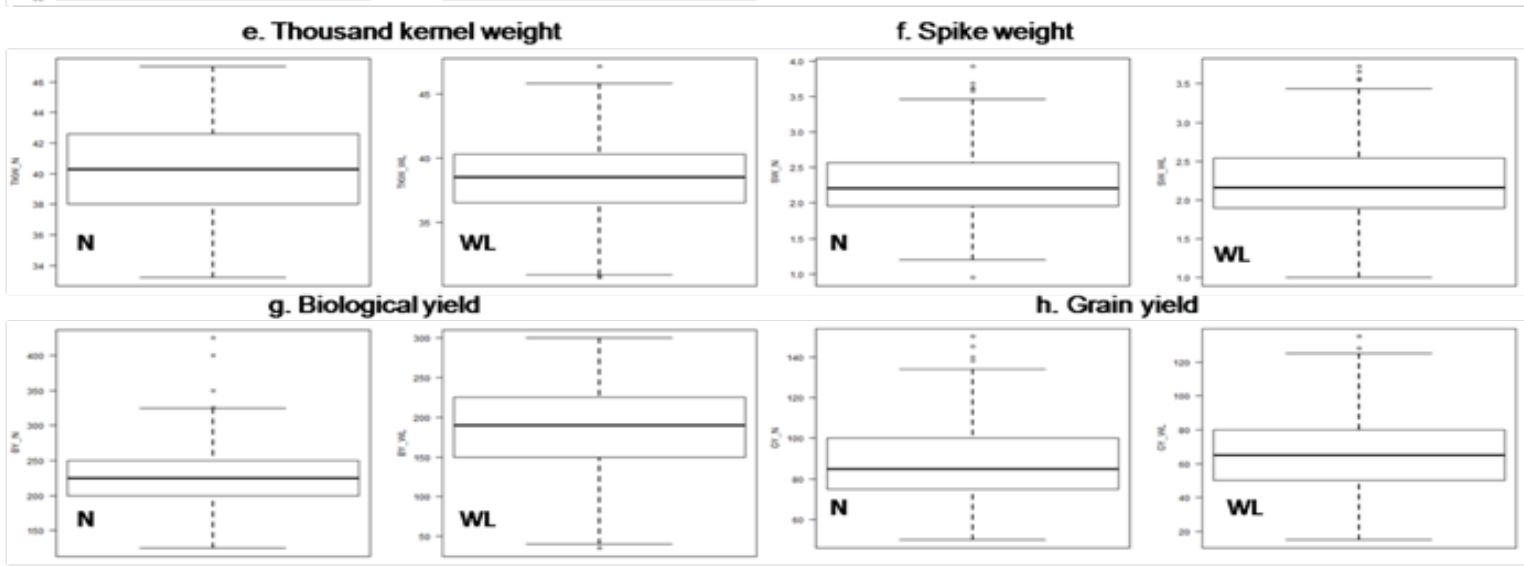

Fig. 1. Box plots representing performance of bread wheat RILs population along with checks for yield component traits under normal and waterlogging conditions where $\mathrm{N}$ : represents normal/ non-waterlogged conditions and WL: represents waterlogged conditions.

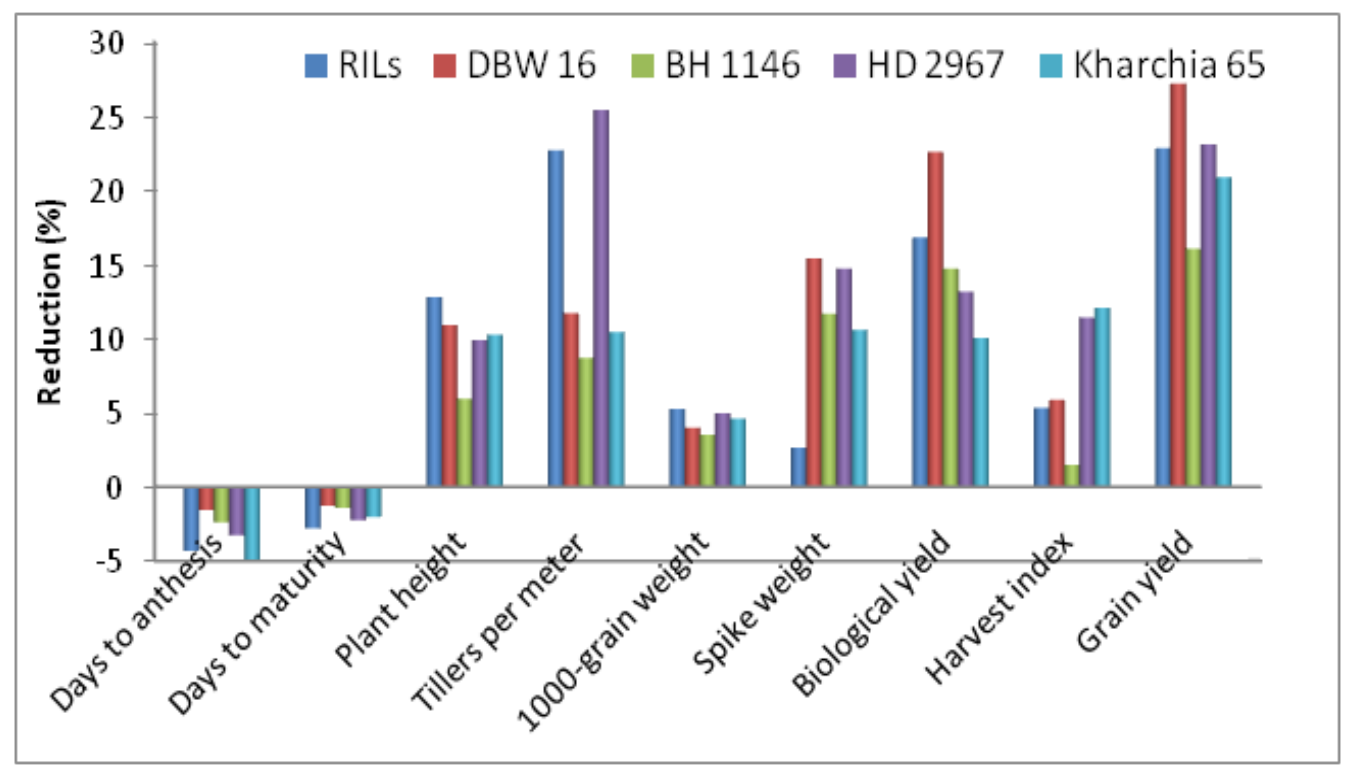

Fig. 2. Comparison of RILs and checks with respect to the traits affected measured in reduction (\%). 


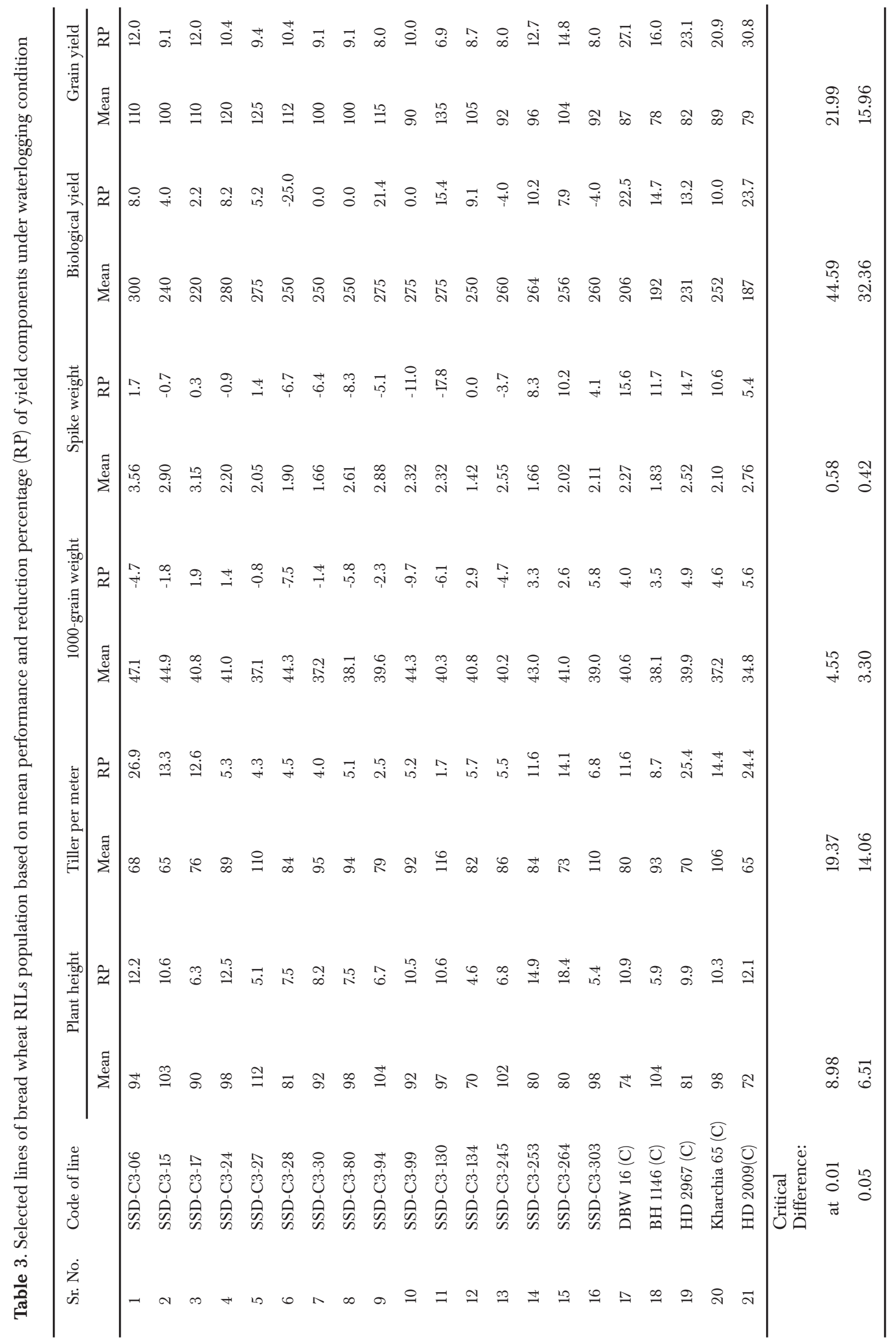


Table 4.Association among grain yield and components traits in bread wheat RILs populations under normal and waterlogging conditions

\begin{tabular}{|c|c|c|c|c|c|c|c|c|c|c|}
\hline Trait & Conditions & $\begin{array}{l}\text { Days to } \\
\text { anthesis }\end{array}$ & $\begin{array}{l}\text { Days to } \\
\text { maturity }\end{array}$ & $\begin{array}{l}\text { Plant } \\
\text { height }\end{array}$ & $\begin{array}{l}\text { Tillers } \\
\text { per } \\
\text { meter }\end{array}$ & $\begin{array}{l}1000- \\
\text { grain } \\
\text { weight }\end{array}$ & $\begin{array}{l}\text { Spike } \\
\text { weight }\end{array}$ & $\begin{array}{l}\text { Biological } \\
\text { yield }\end{array}$ & $\begin{array}{l}\text { Harvest } \\
\text { index }\end{array}$ & $\begin{array}{l}\text { Grain } \\
\text { yield }\end{array}$ \\
\hline \multirow{2}{*}{$\begin{array}{l}\text { Days to } \\
\text { anthesis }\end{array}$} & Normal & - & $0.92^{* *}$ & $0.17^{* *}$ & 0.05 & $-0.27^{* *}$ & $0.13^{*}$ & 0.08 & -0.03 & 0.07 \\
\hline & Waterlogging & - & $0.94^{* *}$ & $0.167^{* *}$ & -0.09 & $-0.26^{* *}$ & 0.04 & -0.05 & $0.14^{*}$ & 0.01 \\
\hline \multirow{2}{*}{$\begin{array}{l}\text { Days to } \\
\text { maturity }\end{array}$} & Normal & & - & $0.19^{* *}$ & 0.02 & $-0.25^{* *}$ & $0.16^{* *}$ & 0.08 & -0.05 & 0.04 \\
\hline & Waterlogging & & - & $0.16^{* *}$ & -0.09 & $-0.21^{* *}$ & 0.09 & -0.04 & $0.13^{*}$ & 0.01 \\
\hline \multirow{2}{*}{$\begin{array}{l}\text { Plant } \\
\text { height }\end{array}$} & Normal & & & - & 0.08 & 0.06 & 0.09 & 0.09 & -0.03 & 0.08 \\
\hline & Waterlogging & & & - & $0.21^{* *}$ & $0.14^{*}$ & 0.03 & $0.22^{* *}$ & -0.03 & $0.18^{* *}$ \\
\hline \multirow{2}{*}{$\begin{array}{l}\text { Tillers per } \\
\text { meter }\end{array}$} & Normal & & & & - & -0.03 & $-0.18^{* *}$ & $0.36^{* *}$ & $0.19^{* *}$ & $0.43^{* *}$ \\
\hline & Waterlogging & & & & - & 0.09 & -0.06 & $0.61^{* *}$ & -0.03 & $0.60^{* *}$ \\
\hline \multirow{2}{*}{$\begin{array}{l}\text { 1000-grain } \\
\text { weight }\end{array}$} & Normal & & & & & - & $0.14^{*}$ & 0.05 & -0.01 & 0.03 \\
\hline & Waterlogging & & & & & - & $0.38^{* *}$ & $0.17^{* *}$ & $0.17^{* *}$ & $0.29^{* *}$ \\
\hline \multirow{2}{*}{$\begin{array}{l}\text { Spike } \\
\text { weight }\end{array}$} & Normal & & & & & & - & $0.11^{*}$ & 0.01 & $0.11^{*}$ \\
\hline & weight & & & & & & - & $0.14^{* *}$ & 0.10 & $0.21^{* *}$ \\
\hline \multirow{2}{*}{$\begin{array}{l}\text { Biological } \\
\text { yield }\end{array}$} & Normal & & & & & & & - & -0.10 & $0.81^{* *}$ \\
\hline & Waterlogging & & & & & & & - & $-0.31^{* *}$ & $0.79^{* *}$ \\
\hline \multirow{2}{*}{$\begin{array}{l}\text { Harvest } \\
\text { index }\end{array}$} & Normal & & & & & & & & - & $0.49^{* *}$ \\
\hline & Waterlogging & & & & & & & & - & $0.31^{* *}$ \\
\hline
\end{tabular}

*, **=Significance at $\mathrm{P}=0.05, \mathrm{P}=0.01$, respectively, RILs- Recombinants inbred lines

among biomass and grain yield under both normal as well as waterlogging conditions (Arguello et al., 2016), while among plant height, tillers number per meter, 1000-grain weight and biological yield with grain yield under waterlogging condition (Singh et al., 2018a) in wheat which supports the present findings. The plant height, tillers per meter, spike weight, and biological yield were found to be positively and significantly correlated with grain yield under waterlogging conditions (Singh et al. 2020). Similarly, the positive and significant association between tillers number per meter and grain yield under normal conditions (Singh et al., 2014), whereas positive and significant association among tillers number per meter and grain yield under both normal as well as waterlogging condition (Singh et al., 2018a). Therefore, it may be concluded that the positive and significant association among component traits as well as with grain yield will enable breeders to select high yielding genotypes through indirect selection for associated traits under waterlogging conditions for enhancing waterlogging tolerance.

\subsection{Selection of Lines for Waterlogging Tolerance}

The findings of the present study showed significant and desirable association among some yield components and grain yield under both normal as well as waterlogging conditions, therefore these traits could be utilized for selecting promising/ tolerant lines for enhancing waterlogging tolerance. Here, higher values of grain yield, biological yield, tiller number per meter, and 1000-grain weight, whereas lower values of reduction percentage in yield components represent relatively more tolerance under waterlogging condition. In the present study, twelve lines were selected out of 340 RILs population by considering superior mean performance and least reduction in grain yield along with some other important yield components under waterlogging condition over the best check used (Table 3). Twelve lines viz., SSD-06, SSD -15, SSD-17, SSD-24, SSD-28, SSD-94, SSD-99, SSD-130, SSD-134, SSD-245, SSD-253, and SSD-264 were selected as the most promising lines that showed high mean performance and least reduction under the waterlogging condition for grain yield, biological yield, and 1000-grain weight over the best check used. Similarly, five lines viz., SSD-27, SSD-30, SSD-80, SSD-130, and SSD-303 were identified as the most promising lines which showed high mean performance and least reduction under the waterlogging condition for grain yield, biological yield, and tillers per meter over the best check used. 
In the earlier study, it was reported that waterlogging tolerance is the ability to maintain high yield under waterlogging conditions relative to drained conditions (Setter and Waters, 2003).

Biological yield has maximum contribution towards waterlogging tolerance in wheat and thus this trait can be used for the selection of tolerant genotypes (Singh $e t$ al., 2020). A simple agronomic trait such as tillering (Singh $e t$ al., 2018b) has also been suggested as a potential selection criterion for high throughput phenotyping of wheat for waterlogging environments in India.

High yielding genotypes provides a potential opportunity for increasing grain yields in target environments (waterlogging condition), but excellent genetic material for future crop improvement can be achieved from both high yielding and waterlogging tolerant genotypes, i.e. genotypes with the highest grain yield in waterlogged relative to drained soils (Singh et al., 2018b).

In the present study, the lines selected based on the traits which showed a strong association with grain yield and also exhibited high mean performance and least reduction under waterlogging conditions, indicating that the selected lines could be used as a potential donor for enhancing

\section{References}

1. Ali R, G Mohammad-Eghbal, JH Saeid, G Mokhtar and S Mohsen. 2012. Impacts of waterlogging on shoot apex development and recovery effects of nitrogen on grain yield of wheat. European Journal of Experimental Biology 2(4): 1000-1007.

2. Araki H, MA Hossain and T Takahashi.2012. Waterlogging and hypoxia have permanent effects on wheat root growth and respiration. Journal of Agronomy and Crop Sciences 198: 264-275.

3. Arguello MN, R Esten-Mason, LR Trenton, NithyaSubramanian, Andrea-Acuna, KA Christopher, NL Dennis, GM Randall and Edward-Gbur. 2016. Performance of soft red winter wheat subjected to field soil waterlogging: Grain yield and yield components. Field Crops Research 194: 57-64.

4. Dickin E and D Wright. 2008. The effects of winter waterlogging and summer drought on the growth and yield of winter wheat (Triticum aestivum L.). European Journal of Agronomy 28: 234-244.

5. Dickin E, S Bennett and D Wright. 2009. Growth waterlogging tolerance.

According to the present findings, it could be concluded that the traits viz., plant height, tillers number per meter, spike weight, 1000-grain weight, biological yield, and harvest index had a positive and significant correlation with grain yield under waterlogging condition, therefore these traits contribute significantly towards grain yield under waterlogging condition. Twelve lines (SSD-06, SSD -15, SSD-17, SSD-24, SSD-28, SSD-94, SSD-99, SSD-130, SSD-134, SSD-245, SSD-253, and SSD-264) were selected based on high mean performance and least reduction under the waterlogging condition for grain yield, biological yield, and 1000-grain weight. The other five lines (SSD-27, SSD-30, SSD-80, SSD-130 and SSD-303)were superior for grain yield, biological yield, and tillers number per meter over the best check used. The selected RILs can be included in the hybridization for improving tolerance to waterlogged soil conditions particularly in areas that receive high rainfall. Further studies on understanding the mechanism of waterlogging tolerance can be undertaken to study the root traits like root porosity and formation of aerenchymatous roots upon stress.

and yield responses of UK wheat cultivars to winter waterlogging. Journal of Agricultural Sciences 147: 127140 .

6. Federer WT. 1956. Augmented (or Hoonuiaku) designs. Hawaii Plant Research 55: 191-208.

7. Gupta SK. 2002. A century of subsurface drainage in India. Irrigation and Drainage Systems 16: 69-84.

8. Jiang D, X Fan, T Dai and W Cao. 2008. Nitrogen fertiliser rate and post-anthesis waterlogging effects on carbohydrate and nitrogen dynamics in wheat. Plant and Soil 304: 301-314.

9. Parelle J, E Dreyer and O Brendel. 2010. Genetic variability and determinism of adaptation of plants to soil waterlogging. In: Mancuso S, Shabala S (eds) Waterlogging Signaling and Tolerance in Plants. Springer-Verlag, Heidelberg, Germany, pp 241-265.

10. Powell N, X Ji, R Ravash, J Edlington and R Dolferus. 2012. Yield stability for cereals in a changing climate. Functional Plant Biology 39: 539-552.

11. Setter TL and I Waters. 2003. Review of prospects for 
germplasm improvement for waterlogging tolerance in wheat barley and oats. Plant and Soil 253: 1-34.

12. Setter TL, I Waters, SK Sharma, KN Singh, N Kulshreshtha, NPS Yaduvanshi, PC Ram, BN Singh, J Rane, G Mc Donald, H Khabaz-Saberi, B Biddulph, R Wilson, I Barclay, R McLean and M Cakir. 2009. Review of wheat improvement for waterlogging tolerance in Australia and India: The importance of anaerobiosis and element toxicities associated with different soils. Annals of Botany 103: 221-235.

13. Singh G, N Kulshreshtha, BN Singh, TL Setter, MK Singh, MS Saharan, BS Tyagi, A Verma and I Sharma.2014.Germplasm characterization, association and clustering for salinity and water logging tolerance in bread wheat (Triticum aestivum). Indian Journal of Agricultural Sciences 84: 1102-10.

14. Singh G, MK Singh, BS Tyagi, JB Singh and P Kumar.2017.Germplasm characterization and selection indices in bread wheat for waterlogged soils in India. Indian Journal of Agricultural Sciences 87: $1139-48$.

15. Singh G, P Kumar, V Gupta, BS Tyagi, C Singh, AK Sharma and GP Singh. 2018a. Multivariate approach to identify and characterize bread wheat (Triticum aestivum) germplasm for waterlogging tolerance in India. Field Crops Research 221: 81-89.

16. Singh G, TL Setter, MK Singh, N Kulshreshtha, BN Singh, K Stefanova, BS Tyagi, JB Singh, BS Kherawatand EG Barrett-Lennard. 2018b. Number of tillers in wheat is an easily measurable index of genotype tolerance to saline waterlogged soils: evidence from 10 large-scale field trials in India. Crop and Pasture Science. 69(6): 561-573.

17. Singh G, P Kumar, V Gupta, BS Tyagi, C Singh, AK Sharma and GP Singh. 2020. Characterizing waterlogging tolerance using multiple selection indices in bread wheat (Triticum aestivum). Indian Journal of Agricultural Sciences 90 (3): 662-65.

18. Stringer JK and BR Cullis. 2002. Application of spatial analysis techniques to adjust for fertility trends and identify interplot competition in early stage sugarcane selection trials. Australian Journal of Agricultural Research 53: 911-8.

19. Zhang H, NC Turner, ML Poole and N Simpson. 2006. Crop production in the high rainfall zones of southern Australia-potential, constraints and opportunities. Australian Journal of Experimental Agriculture 46: 1035-1049.

20. Zhang X, Y Fan, S Shabala, A Koutoulis, L Shabala, P Johnson, $\mathrm{H} \mathrm{Hu}$ and $\mathrm{M}$ Zhou. 2017. A new majoreffect QTL for waterlogging tolerance in wild barley (H. spontaneum). Theoretical and Applied Genetics 130: 1559-1568.

21. Zhang X, S Shabala, A Koutoulis, L Shabala, P Johnson, D Hayes, DS Nichols and M Zhou. 2015. Waterlogging tolerance in barley is associated with faster aerenchyma formation in adventitious roots. Plant and Soil 394(1):355-372. 